\title{
Israel in einer altägyptischen Inschrift.
}

\author{
Von G. Steindorff.
}

Flinders Petrie hat bei den Ausgrabungen, die er in diesem Winter auf dem westlichen Nilufer bei Theben unternommen hat, in einem von Merneptah, dem Sohne und Nachfolger Ramses' II., erbauten Heiligtum eine Gedenktafel aus schwarzem Granit gefunden, die auch für die alttestamentliche Forschung von grosser Wichtigkeit ist. Sie enthält nämlich die erste ägyptische Erwähnung des Volkes Israel. ${ }^{\text {I }}$

Die Tafel wurde zuerst von König Amenophis III. (um I 450 v. Chr.) mit einem seine Bauten verherrlichenden Texte bedeckt, später anderweitig verwendet und auf der Rückseite von Merneptah mit einer neuen Inschrift beschrieben. Diese Urkunde Merneptah's berichtet von dem Siege, den der König in seinem 5. Regierungsjahre über die Libyer errungen, und schliesst an diese Schilderung noch eine in Versen gehaltene Verherrlichung der Macht des Herrschers. Hier heisst es:

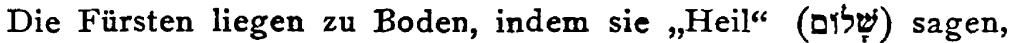

Nicht einer erhebt sein Haupt unter den Neunbogenvölkern;

Verwüstet ist Libyen,

Cheta ist beruhigt,

Kanaan ist erobert sehr böse(?);

I Vgl. Spiegelberg, Die erste Erwähnung Israels in einem ägyptischen Texte, in den Sitzungsber. Berl. Ak. 1896, 593 ff. Den von Spiegelberg veröffentlichten Text legen wir den folgenden Bemerkungen zu Grunde.

2 d. h. die Erbfeinde der Ägypter. 
Fortgeführt ist Askalon,

Überwältigt ist Gezer;

$Y \cdot n u-C m$ ist vernichtet,

$Y$-si-r.'l ist ein . . o ohne Frucht;

Charu ist eine Witwe Ägyptens,

Alle Länder insgesamt sind in Frieden.

In dieser Übersetzung sind an Stelle der ägyptischen Länder- und Ortsbezeichnungen, soweit ihre Identificirung gesichert ist, die uns geläufigen Namen gesetzt worden. Von den übrigen Lokalitäten ist $Y-n u-C m$ (ינעם) wahrscheinlich in Nordpalästina ostwärts von Tyrus zu suchen $^{x}$; unter Charu verstehen die Ägypter das südliche (oder süd-westliche) Palästina. $Y$-si-r-' $l$, in Hieroglyphen

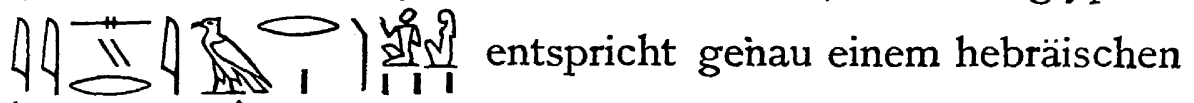

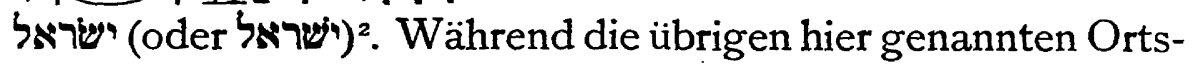
namen, gleichviel ob sie Länder oder Städte bezeichnen, im Ägyptischen das Länderdeterminativ haben, ist, worauf auch Spiegelberg hinweist, der Name $Y$-si-r-'l mit dem Determinativ für Menschen versehen. Es ist also kein Land Israel, sondern das Volk oder der Stamm Israel gemeint.

Für die historische und geographische Beurteilung muss man sich nun vor Augen halten, dass der vorliegende Text ein poetischer ist. Die Verse sind zur Verherrlichung des Pharao geschrieben und wenn darin in allgemeinen Phrasen von eroberten oder "beruhigten“ Ländern und Städten gespirochen wird, so braucht durchaus nicht der angesungene Merneptah ihr Eroberer und Beruhiger zu sein. Von einem Feldzug des Königs gegen Libyen wissen

1 Vgl. M. Müller, Asien und Europa S. 201.

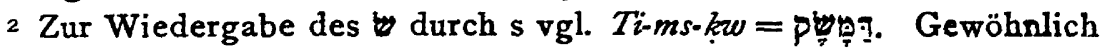
entspricht dem s ein $\forall$. 
wir freilich; ob aber eine Beruhigung Cheta's unter ihm stattgefunden hat, ist mehr als zweifelhaft. ${ }^{x}$ Ebenso bleibt es unsicher, ob Askalon und Gezer, $Y-n u-C m$ und die Israel von ihm zu Vasallen gemacht worden sind oder ob sie sich nicht etwa schon seit seinem Vater Ramses unter ägyptischer Botmässigkeit befanden. Kurz wir sehen keine Veranlassung, aus diesen Versen auf einen Feldzug Merneptah's in Palästina, auf eine Erhebung und Niederwerfung palästinensischer Stämme zu schliessen. ${ }^{2}$

Auch die geographische Bestimmung von Israel wird durch den poetischen Charakter des Textes erschwert, da auf die Anordnung und wohl auch Auswahl der Namen gewiss dichterische Absichten (Metrum, vielleicht auch Alliteration) eingewirkt haben.

Im Eingange sind Libyen, Cheta und Kanaan blind zusammen gewürfelt. Dann folgen Askalon, Gezer, Jenu am, bei denen allerdings eine geographische Anordnung von Süden nach Norden gegeben zu sein scheint. Ob nun diese Reihenfolge sich noch auf Israel erstreckt und dieses nördlich von Jenúam, also im nordöstlichen Palästina $z u$ suchen ist, oder ob auf $Y$-nu-Cm Y-s̈̈r-'l zufällig oder vielleicht der Alliteration wegen folgt, lässt sich schwer entscheiden. Immerhin dürfen wir aus der ganzen Umgebung, in der das Volk Israel genannt wird, folgern, dass es sich damals in Palästina aufhielt. Und dies ist der historische Gewinn, den der von Petrie gefundene Text uns gebracht hat. Während man früher auf Grund von Ex. I, I 2 vielfach angenommen hatte, dass die Bedrückung der Israeliten in Ägypten, die Erbauung

I Für einen friedlichen Verkehr mit den Hethitern spricht, worauf mich Ed. Meyer aufmerksam macht, der Umstand, dass Merneptah Ge. treideschiffe zur „Ernährung“ dieses Landes schickte, Mar. Karn. 53, Z. 24.

2 Ehe ich den Wortlaut des Textes kannte, habe ich selbst in den M. u. N. des Paläst. Ver. I896, 45 f. einen Feldzug des Königs angenommen. Auch Spiegelberg (a. a. O.) thut dies. 
der Vorrathsstädte Pithom und Ramses unter Ramses II. stattgefunden, und dass der Auszug (nach Ex. 2, 23) sich unter Ramses II. Sohn Merneptah vollzogen habe, werden wir jetzt belehrt, dass die Israeliten zur Zeit Merneptall's, also gegen Ende des I3. vorchristlichen Jahrhunderts, bereits in Palästina eingerückt und dabei mit den Ägyptern in feindliche Berührung gekommen waren.

Durch dieses neue Datum gewinnt auch Zimmern's Vermutung, dass die in den Tell-Amarna-Briefen erwähnten Chabiri-Leute mit den Hebräern identisch sind, an Wahrscheinlichkeit. ${ }^{x}$ Die Hebräer würden dann um I400 ihre Angriffe gegen das Westjordanland begonnen haben und um I 200 v. Chr. im Besitze eines Teils von Palästina gewesen sein. Die Occupation dürfte dann wohl in die Zeit nach Amenophis IV. fallen, als das ägyptische Reich durch innere Wirren zerrüttet war und sich wenig um seine auswärtigen Besitzungen kümmern konnte, also in dieselbe Zeit, in die auch die Gründung des grossen Hethiterreichs fällt.

I Vgl. Zeitschr. d. Pal.-Ver. XIlI, I37 ff. 